\title{
Estudo de egressos de cursos de graduação: subsídios para a autoavaliação e o planejamento institucionais ${ }^{1}$
}

\section{Study of alumni from undergraduate courses: grants for institutional self-assessment and planning}

\author{
Wagner Bandeira Andriola ${ }^{2}$
}

\begin{abstract}
RESUMO
O texto relata estudo com 586 egressos de cursos de graduação, através do uso de questionário online, no qual se focou a obtenção de informações acerca: (a) da situação laboral; (b) do grau de satisfação com a área de inserção laboral e com a remuneração; (c) das opiniões a respeito da adequação do currículo às expectativas pessoais e às demandas do mercado de trabalho; (d) da necessidade de aprimorar a formação recebida no âmbito da graduação. Os resultados identificaram elevada proporção de egressos inseridos no mercado de trabalho, atuando na mesma área de formação e com renda mensal individual variando de 1,5 a três salários mínimos. Ademais, proporcionaram informações sobre o reconhecimento majoritário dos egressos quanto à qualidade: (i) da formação recebida; (ii) da gestão acadêmica do curso; (iii) da adequação curricular para o exercício profissional; (iv) do estágio curricular obrigatório; (v) das salas de aula e espaços de convivência.

Palavras-chave: Ensino superior; avaliação educacional; estudo de egressos; autoavaliação institucional.
\end{abstract}

\section{ABSTRACT}

This paper reports a study with 586 alumni from undergraduate courses through the use of an online questionnaire, which focused on obtaining

DOI: $10.1590 / 0104-4060.36720$

1 Estudo financiado pelo Conselho Nacional de Desenvolvimento Científico e Tecnológico (CNPq - Processo 304645/2010-9 - Produtividade em Pesquisa).

2 Universidade Federal do Ceará. Fundamentos da Educação, da Faculdade de Educação. Fortaleza. Ceará, Brasil. Av. da Universidade, nº 285. Benfica. CEP: 60020-180. 
information about: (a) the employment situation; (b) the degree of satisfaction with the area of job placement and their payment; (c) opinions on the appropriateness of the curriculum to personal expectations and demands of the labor market; (d) the need to enhance the training received at the undergraduate level. The results identified a high proportion of graduates in the job market, working in the same area of training and with individual monthly income ranging from 1.5 to three minimum wages. In addition, they provided information on the major recognition for quality by graduates concerning: (i) the training received; (ii) the academic course management; (iii) the adaptation of curricula for professional practice; (iv) the compulsory traineeship; (v) classrooms and living spaces.

Keywords: Higher education; educational assessment; study on alumni; institutional self-assessment.

\section{Introdução}

O Sistema Nacional de Avaliação da Educação Superior (SINAES), instituído pela Lei Federal $n^{\circ} 10.861$ (14/04/2004), posteriormente regulamentado pela Portaria Ministerial $n^{\circ} 2.051$, (09/07/2004), fundamenta-se em diversos pilares teóricos e epistemológicos (BRASIL, 2004). A busca da participação e do engajamento dos vários atores das Instituições de Educação Superior (IES) é um desses fundamentos (BELLONI, 1999; RISTOFF, 2000). Há que se mencionar a multiplicidade de dimensões previstas de serem avaliadas, dentre as quais os egressos. Conforme o Roteiro de Autoavaliação Institucional 2004, os principais objetivos da avaliação de egressos são: verificar a inserção profissional e a participação destes na vida da Instituição de Ensino Superior (IES), muito embora reconheça-se que estes não são os únicos partícipes das numerosas atividades acadêmicas e administrativas de uma IES (ANDRIOLA, 2003a, p. 483, 2003b).

\section{Natureza das atividades desenvolvidas no interior de uma IES}

A Figura 1 reveste-se em tentativa de abstrair e representar graficamente as atividades desenvolvidas por uma IES, destacando interações e repercussões sobre o contexto social. 


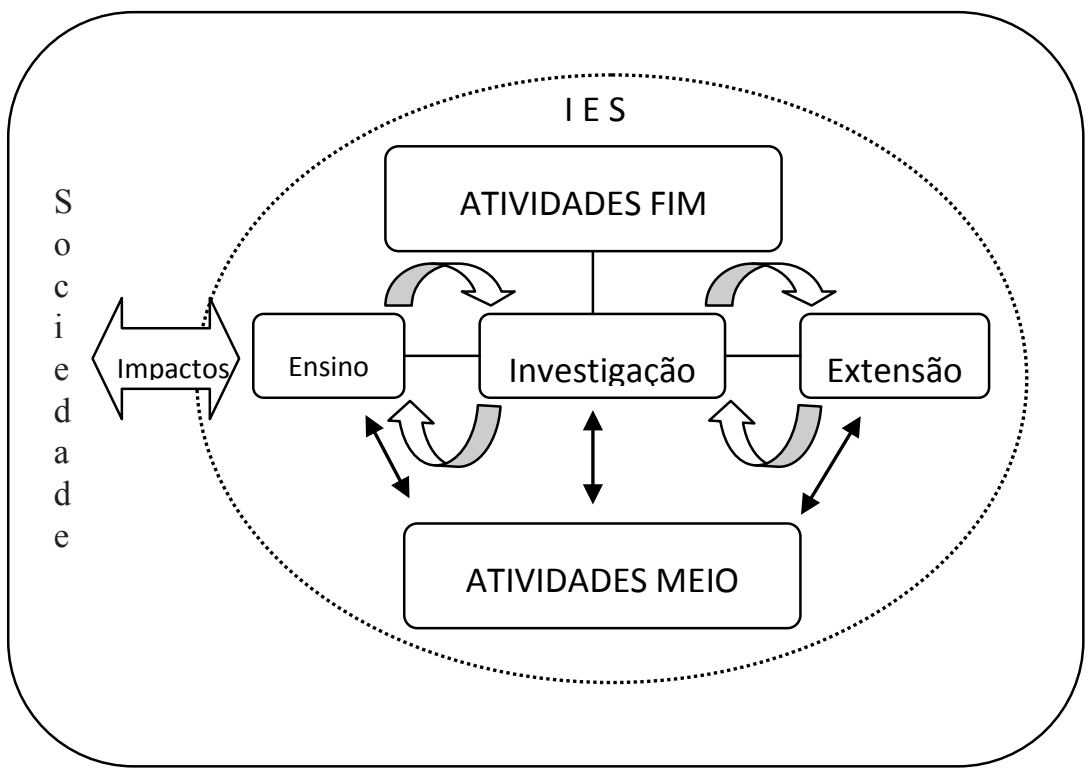

FIGURA 1 - ATIVIDADES DESENVOLVIDAS NO SEIO DE UMA IES E SUAS REPERCUSSÕES NA SOCIEDADE

FONTE: Andriola (2006).

A Figura 1 baseia-se na ideia de que uma IES (representada pela elipse) é um sistema semiaberto, conforme destacado por Dias Sobrinho e Ristoff(2003), e por Cavalieri, Macedo-Soares e Thiollent (2004). O mencionado sistema educacional está em sistemática e dinâmica interação com o contexto social no qual está imerso (o retângulo); suas atividades e seus produtos têm relevantes repercussões sobre a sociedade na qual está inserido, ao mesmo tempo em que também sofre a influência da mesma (representada pela seta de duplo sentido que interliga a IES com a sociedade). Sendo assim, nada é mais relevante do que a investigação das repercussões sociais das atividades de uma IES, através, por exemplo, do acompanhamento sistemático dos seus egressos; mapeando opiniões, atitudes e crenças acerca da universidade e da sociedade; identificando e avaliando o valor agregado pela IES; verificando a opinião: (i) dos empregadores e (ii) de setores da sociedade civil organizada, acerca da adequação e da pertinência da formação profissional e cidadã dos recursos humanos formados.

Na Figura 1 há ênfase sobre dois conjuntos relevantes de atividades institucionais, distintas entre si, porém complementares. O primeiro grupo pode ser chamado de atividades fim, pois elas conformam o célebre e conhecido tripé de toda e qualquer IES com porte de Universidade: o ensino (de graduação e de 
pós-graduação), a investigação científica (no âmbito da graduação e da pós-graduação) e a extensão.

Os elementos do mencionado tripé de atividades representativas de toda e qualquer universidade estão em constante interação entre si. Em suma: o ensino exerce influência sobre a investigação e sobre a extensão, ao mesmo tempo em que também sofre seus efeitos (na Figura 1 a interação é representada por setas de duplo sentido que interligam essas três dimensões institucionais). Conforme destacam Gell-Mann (2003), Popper (1972), Puente Viedma (1993), Serres (1998) e Wilson (1999): toda e qualquer atividade cientifica tem como principal objetivo buscar identificar relações válidas entre variáveis, não descartando as interações válidas e significativas que podem ser estabelecidas entre as mesmas. Sendo assim, um dos mais relevantes objetivos da avaliação de IES é tentar identificar a qualidade e a natureza das interações entre o ensino, a investigação científica e a extensão (AMARAL, 1999).

Agora bem, para que as atividades finalísticas (o ensino, a investigação científica e a extensão) venham a ser executadas a contento, deverá existir outro conjunto de processos que potencialize o alcance das primeiras. Esse segundo conjunto é formado pelas atividades meio, que pode ser exemplificado através da adequação: (i) da gestão administrativa e de pessoal; (ii) do planejamento estratégico institucional; (iii) da sustentabilidade financeira; (iv) das políticas internas voltadas a combater a evasão discente; (v) da adequação das bibliotecas, dos laboratórios e das salas de aula, dentre ampla diversidade de outros aspectos institucionais.

Conforme destaca a Figura 1, as atividades fim e as meio interagem entre $s i$, isto é, uma influencia a outra ao mesmo tempo em que sofre sua ação. Por exemplo: as atividades de ensino, de investigação científica e de extensão serão influenciadas pela qualidade física das salas de aula, da adequação da iluminação, da ventilação e mesmo da segurança proporcionada aos seus usuários; também sofrerão com a qualidade do acervo disponibilizado pelas bibliotecas. Esses dois aspectos destacados dependerão, por seu turno, da sustentabilidade financeira da IES. Com essa exemplificação desejamos ressaltar a estreita relação que há entre as finalidades da IES (atividades fim) e as dimensões que lhes dão suporte (atividades meio). Portanto, uma vincula-se à outra e tal ligação deve ser objeto da avaliação institucional.

Retomando a discussão em torno das repercussões sociais das atividades desenvolvidas por uma IES, há que se enfatizar o acompanhamento de egressos como relevante estratégia institucional para obtenção de informações acerca da qualidade da formação discente e de sua adequação às novas exigências da sociedade e do mercado de trabalho (ANDRIOLA; McDONALD, 2003). Para tal, apresentaremos resultados oriundos de estudos efetivados com egressos de IES. 


\section{Estudos com egressos de cursos de Graduação: exemplos presentes na literatura}

Iniciemos destacando uma constatação: raros são os estudos visando o acompanhamento de egressos de cursos de graduação, realizados pelas IES brasileiras. A revisão sobre o tema corroborou tal aridez. Não obstante, serão apresentadas, a seguir, informações acerca de 11 pesquisas com egressos, sendo cinco oriundas de autoavaliação institucional.

A Secretaria de Planejamento da Universidade de Brasília (UnB) procurou traçar o perfil de alguns dos seus ex-alunos inseridos no mercado de trabalho. Para tal, estudos foram realizados entre 1993 e 2002 com os egressos dos cursos de Arquitetura e Urbanismo e Desenho Industrial (QUEM é o profissional..., 2005). O principal objetivo foi compreender o impacto das ações institucionais na formação desses alunos, as fragilidades da formação oferecida em comparação às exigências do mercado e também as competências desenvolvidas com a formação ou mesmo as que deveriam ser desenvolvidas. Na pesquisa, utilizou-se amostra aleatória simples de egressos do período de 1993 a 2002 de ambos os cursos, tendo sido aplicado questionário via internet. A amostra de arquitetos foi formada por 81 egressos de uma população de 495 (16,3\% do total), sendo a amostra de desenhistas industriais formada por 66 egressos de uma população de 204 (32,4\% do total de egressos).

Os resultados constataram que significativa parte dos egressos já exercia algum tipo de atividade na área de formação, ainda durante a realização do curso e, por conta disso, conseguiram ingressar no primeiro emprego em menos de três meses após a formatura. Outros dados deram conta que, dentre os arquitetos, $74,1 \%$ já estavam inseridos no mercado de trabalho, desenvolvendo atividades como profissionais liberais e servidores públicos. A faixa salarial bruta desses profissionais no mercado estava entre $\mathrm{R} \$ 1.200,00$ e $\mathrm{R} \$ 4.800,00$. Porém, 50\% dos entrevistados alegaram estar insatisfeitos com a remuneração recebida, apesar de 51,3\% asseverarem estar satisfeitos com o trabalho que executavam.

Os desenhistas industriais demoraram até seis meses para ingressarem no mercado de trabalho após a conclusão do curso. Do contingente de egressos inseridos no mercado de trabalho, $77,77 \%$ atuavam como profissionais do setor privado e tão-somente $22,22 \%$ como servidores públicos. Ainda no que tange aos egressos inseridos no mercado de trabalho, 38,89\% deles estavam satisfeitos com a remuneração recebida (entre $\mathrm{R} \$ 1.200,00$ e $\mathrm{R} \$ 4.800,00$ ) e $61,11 \%$ estavam satisfeitos ou muito satisfeitos com a área na qual atuavam.

A Universidade Federal da Paraíba (UFPb), através da sua Pró-Reitoria de Graduação (PRG), apresenta relevantes dados dos egressos dos cursos de 
graduação $^{3}$, relativos ao segundo semestre letivo de 1994. Tais informações incluem as proporções de diplomados, de cancelamentos e de transferências, segundo a respectiva Unidade Acadêmica. De acordo com os mesmos, a proporção de diplomados no âmbito da IES sequer atinge, em média, 50\% dos discentes ingressantes. Dentre os casos de cancelamento de matrícula, tal proporção também ronda os $50 \%$ dos ingressantes, no âmbito da UFPb, sendo que, no caso do Centro de Ciências Exatas e da Natureza (CCEN), tal valor é superior à média institucional.

A Universidade de São Paulo (USP) efetivou estudo com 217 egressos de 1990 a 1996 do curso de Nutrição, por meio de questionários enviados via correios (GAMBARDELLA; FERREIRA; FRUTUOSO, 2000). Através da análise das informações brindadas por 89 questionários devolvidos aos pesquisadores (o que corresponde a uma taxa de retorno de $42 \%$ ), alguns pontos relevantes foram aclarados. Por exemplo: 79,8\% dos nutricionistas trabalhavam na respectiva área de formação, enquanto $14,6 \%$ não estavam ainda inseridos no mercado de trabalho e 5,6\% estavam atuando em áreas distintas à formação recebida. Segundo os dados, a maioria dos entrevistados $(59,1 \%)$ tinha remuneração superior a 10 salários mínimos e 37,1\% estava realizando algum curso de aprimoramento, sendo que $29,2 \%$ realizavam pós-graduação na área de nutrição, enquanto $21,3 \%$ dos entrevistados referiram estar insatisfeitos no exercício da profissão.

A Coordenadoria de Avaliação Institucional (CAI) da Universidade Federal do Ceará (UFC) realizou estudo com 101 egressos de cursos de graduação do período 2003-2004, através do uso de questionário enviado via telefone (ANDRIOLA, 2006). Os resultados detectaram que cerca de 50\% dos egressos estavam inseridos no mercado laboral $(n=50)$, sendo que a maioria deste grupo era composta por mulheres, solteiras, com idade média de 24,5 anos. Quando indagados acerca do tipo de atividade na qual atuavam, um grupo significativo $(47 \%$ ou $n=23)$ estava no serviço público, com a ampla maioria exercendo a profissão na qual havia recebido formação $(72 \%$ ou $n=36)$ e com elevado nível de satisfação $(63,5 \%$ ou $\mathrm{n}=32)$. Cumpre destacar, por relevante: metade deste grupo de egressos $(n=25)$ havia participado de atividades de iniciação científica e/ou estágio remunerado em empresas durante a graduação; a contundente maioria $(88 \%$ ou $n=43)$ revelou necessidade de adquirir formação profissional mais profunda.

O estudo efetivado pelo Centro Federal de Ensino Tecnológico do Rio Grande do Norte (CEFET/RN) foi realizado com 169 recém-concludentes dos

3 Para tal, ver o sítio: <http://www.prg.ufpb.br/cspa/fasciculos/fasciculo\%20IV/analise_g. $\mathrm{htm}>$. Acesso em: 24/05/2006. 
cursos oferecidos, através do uso de um questionário aplicado via telefone, e-mail e correios. Obteve-se taxa de retorno de 78 questionários, o que corresponde a aproximadamente $46 \%$ da amostra original de 169 sujeitos.

Os resultados do mencionado estudo indicaram que os egressos consideraram o ensino e o estágio profissional da referida instituição educacional como aspectos muito bons, conforme ressaltado por mais de $70 \%$ dos entrevistados. Outro ponto interessante: mais de $80 \%$ dos egressos revelaram interesse em retornar à IES para participar de cursos continuadores da formação recebida (ROCHA; FILGUEIRA; DA COSTA; GALVÃO; VIANA, 2005).

Colenci e Berti (2012) desenvolveram estudo com egressos de enfermagem de IES privada com os objetivos de apreender e analisar percepções em relação ao processo de formação, frente às condições de inserção no mercado de trabalho e às demandas vivenciadas no cotidiano profissional. Para tal foram pesquisados 104 egressos, divididos em três grupos, a saber: profissionais que atuam como enfermeiros; profissionais que atuam como técnicos ou auxiliares de enfermagem; profissionais que não atuam na área de formação básica.

Os resultados apontaram falhas na formação dos egressos, destacando-se a falta de conhecimento sobre gerência; estágios e carga horária insuficientes para o desenvolvimento de habilidades necessárias à assistência; além da falta de incentivos à pesquisa. Assim, o estudo possibilitou a revisão do projeto político-pedagógico, destacando-se a necessidade de um ensino voltado para o desenvolvimento de competências, englobando a atuação do enfermeiro nas quatro dimensões do processo de cuidar: gerência, assistência, educação e pesquisa.

A pesquisa levada a cabo por Carrijo, Bezerra, Munari e Medeiros (2007) objetivou identificar os fatores determinantes da empregabilidade de egressos de graduação em enfermagem de uma universidade pública. Para tal, realizou entrevistas semiestruturadas com 41 egressos do curso de graduação em enfermagem de uma universidade pública de Goiânia (GO). Os dados revelaram que a maioria trabalhava no Programa Saúde da Família (PSF) e sentia-se preparada para o exercício profissional a partir da formação acadêmica recebida. Não obstante, $19,5 \%(\mathrm{n}=8)$ asseveraram sentir-se despreparados para o exercício profissional, dada a discrepância entre a realidade acadêmica e as exigências do mundo do trabalho.

O estudo realizado por Meira e Kurcgant (2009) teve como objetivo relacionar a importância atribuída ao ensino de graduação com os pressupostos das Diretrizes Curriculares Nacionais (DCNs) para a enfermagem. Os resultados obtidos junto a 32 egressos sugerem o fortalecimento da prática interdisciplinar e apontam a necessidade de otimizar a distribuição de conteúdos e de carga horária das disciplinas que são destinadas à formação de competências administrativas. Sugerem, ainda, a aproximação do estudante à realidade profissional, 
com estágios em instituições diversas, propiciando as condições geradoras de um aprendizado significativo e consistente, de forma a garantir desempenho profissional adequado.

Consideram, assim, que os conteúdos da administração devam permear, ao longo do curso, a concretização do currículo proposto e fazer a interlocução com outras disciplinas, de tal forma que promovam um ensino integrado e contextualizado. Essas reflexões mostram que as dificuldades enfrentadas pelos egressos podem ser dirimidas por um programa de ensino planejado e concretizado a partir das Diretrizes Curriculares Nacionais (DCNs).

O trabalho de Cordioli e Batista (2007) investigou a formação universitária em Odontologia, a partir de egressos diplomados e em busca de pós-graduação. Os dados foram obtidos por meio de questionário com assertivas relacionadas com a temática pesquisada e da análise do grau de concordância e/ou discordância. Os principais achados evidenciam aspectos essenciais que ainda dificultam a concretização do perfil de egresso preconizado pelas Diretrizes Curriculares Nacionais (DCNs), especialmente no tocante ao preparo para uma prática generalista da profissão. Salientam-se a falta de articulação da teoria com a prática, uma visão da Odontologia descontextualizada da realidade com consequente despreparo para atuação no mercado de trabalho, a formação inadequada para o trabalho no contexto do Sistema Único de Saúde (SUS), o preparo inadequado para ações ligadas à administração e ao gerenciamento da própria prática.

Santos e Sanna (2003) realizaram pesquisa junto a 80 egressos do curso de enfermagem de IES particular da grande São Paulo. A caracterização demográfica dos 80 egressos indicou que a população era constituída por adultos jovens, predominantemente do sexo feminino, solteiro e sem filhos, moradores da região em que se situa a universidade. A maioria já era profissional da área da saúde quando concluiu o curso; boa parte dos egressos já possuía o título de especialista em Enfermagem e muitos pretendiam obtê-lo; poucos estavam inseridos em programas de mestrado, mas metade dos respondentes manifestou interesse nesse nível de formação. Finalmente, cumpre destacar que a inserção dos egressos do curso no mercado de trabalho se deu rapidamente após a conclusão do curso, muitos tendo já experimentado mais de um emprego.

O estudo realizado por Bardagi et al. (2008) buscou conhecer a formação e as trajetórias de trabalho dos novos profissionais de psicologia formados por uma universidade pública federal. Um questionário semiestruturado com 18 questões sobre a atuação profissional, avaliação da formação recebida e sugestões para mudanças curriculares foi enviado via internet ou correio a 143 egressos formados entre 1997 e 2004, com taxa de retorno de 55,2\% $(\mathrm{n}=79)$.

Os resultados indicaram que $88 \%$ dos egressos $(n=70)$ atuavam como psicólogos, sendo que um grupo significativo $(41,7 \%$ ou $n=33)$ teve a ativida- 
de clínica como primeira inserção e $88,6 \%$ buscaram formação complementar $(\mathrm{n}=70)$. Em relação ao curso, apontam a Psicologia clínica como a área mais privilegiada durante a graduação $(29,4 \%$ ou $n=23)$. A criação de disciplinas inexistentes e maior diversidade teórica foram as principais sugestões de mudança.

\section{Objetivos do estudo}

A partir do exposto, a presente pesquisa teve como objetivos: a) identificar a situação laboral dos egressos dos cursos de graduação; b) verificar o grau de satisfação com a área de inserção laboral, bem como com a remuneração; c) mapear as opiniões acerca da adequação do currículo às expectativas pessoais e às demandas do mercado de trabalho; $\mathrm{d}$ ) averiguar a necessidade de aprimorar a formação recebida no âmbito da graduação. Para que tais objetivos fossem alcançados foi efetivado estudo de campo do tipo ex post-facto com os egressos dos cursos de graduação da Universidade Federal do Ceará (UFC) do período 2009/2011.

\section{Populações e amostras de egressos}

A população estudada compunha-se dos universitários egressos dos cursos de graduação da UFC dos anos $2009(\mathrm{~N}=2.481), 2010(\mathrm{~N}=2.586)$ e $2011(\mathrm{~N}=2.704)$, totalizando, assim 7.771 ex-alunos. A amostra investigada foi formada por 586 egressos respondentes ao questionário enviado via e-mail, o que representou $7,54 \%$ do total.

\section{Instrumento usado na coleta de dados}

O instrumento utilizado para a coleta de dados foi um questionário aplicado em plataforma online e composto por duas partes: a primeira destinada à identificação dos respondentes e a segunda composta por questões (abertas e fechadas) que abordaram os seguintes aspectos: situação laboral dos egressos; grau de satisfação com a área de atuação e com a remuneração; tempo necessário 
para obter o primeiro emprego, após a formatura; faixa salarial; necessidade de aprimorar a formação recebida na universidade; e adequação do currículo às necessidades profissionais dos entrevistados.

\section{Procedimento usado na coleta de dados}

O link que foi desenvolvido para alojar o questionário eletrônico destinado ao estudo foi enviado à população de 7.771 egressos do período 2009 a 2011 da UFC, através dos respectivos e-mails. Durante 90 dias (meses de março a maio de 2012) o questionário online esteve aberto para a recepção das respostas dos partícipes. Conforme já referido, a taxa de retorno atingiu 7,54\%, o que significou a participação efetiva de amostra composta por 586 egressos.

\section{Principais resultados}

Perfil dos egressos durante a formação de graduação

Os resultados indicaram que a maioria dos egressos $(66,9 \%$ ou $n=392)$ já desempenhava alguma atividade remunerada durante a formação em nível de graduação, sendo que $53,1 \%(\mathrm{n}=208)$ atuava no setor terciário (prestação de serviços), vindo, em seguida, o setor público $(28,6 \%$ ou $n=112)$, em que atuavam como servidores públicos federais, estaduais ou municipais; e 13,8\% (n $=54$ ) atuavam no setor industrial. Outro dado interessante: parcela substantiva dos egressos atuava na área em que estava recebendo formação universitária $(\mathrm{n}=293$ ou 74,7\%). A renda individual dos estudantes que trabalhavam durante o processo de formação na graduação variou de $\mathrm{R} \$ 500,00$ (quinhentos reais) a $\mathrm{R} \$ 2.000,00$ (dois mil reais).

Perfil dos egressos após a diplomação

Após a diplomação, a proporção de egressos atuando no mercado laboral atingiu a expressiva marca de $86,3 \%(\mathrm{n}=506)$, com o setor terciário ainda sendo o mais relevante $(43,5 \%$ dos egressos ou $n=220)$, vindo, em seguida, o setor público (no qual $36,4 \%$ ou $n=184$ atuavam como servidores públicos federais, estaduais ou municipais); e 12,6\% $(\mathrm{n}=64)$ atuavam no setor industrial. Outro aspecto a ser destacado: parcela substantiva dos egressos atuava na área em 
que havia recebido formação universitária $(\mathrm{n}=414$ ou 81,8\%). Cabe destacar, por oportuno, que a renda média dos estudantes que obtiveram trabalho após a formação na graduação variou de $\mathrm{R} \$ 1.350,00$ (mil trezentos e cinquenta reais) a R \$ 3.500,00 (três mil e quinhentos reais). Finalmente, cabe destacar, ademais, que o tempo médio para que os egressos obtivessem seu primeiro trabalho remunerado foi de 30 meses após a formação.

\section{Opinião dos egressos sobre a formação de graduação}

Para iniciar, cabe destacar: de acordo com $49 \%$ dos egressos de cursos de graduação da UFC $(\mathrm{n}=287)$, a formação recebida pode ser considerada muito boa ou excelente. Não obstante, para $15 \%(\mathrm{n}=88)$ a formação recebida pode ser considerada muito ruim ou razoável. Este segundo grupo, apesar de minoritário, revela a necessidade de se recorrer a um estudo de maior profundidade, com vistas a identificar os cursos nos quais há maior concentração de alunos com esta visão, bem como os fatores apontados por estes para que tal situação ocorra.

Para a maioria dos egressos $(68,3 \%$ ou $\mathrm{n}=400)$ a qualidade de gestão do curso de graduação pode ser considerada excelente, muito boa ou boa. No entanto, para $31,6 \%(\mathrm{n}=185)$ a qualidade da gestão do curso pode ser considerada muito ruim ou razoável. Embora minoritário, este segundo grupo revela a demanda por estudo de maior nível de profundidade, de modo a se identificar os cursos nos quais há maior concentração de alunos com este tipo de visão, bem como os fatores apontados por estes para que tal situação exista.

No que tange à qualidade do currículo para a formação profissional idealizada pelos egressos, parcela significativa $(42,1 \%$ ou $n=247)$ referiu que este aspecto pode ser considerado excelente, muito bom ou bom. No entanto, para a maioria $54,8 \%(\mathrm{n}=321)$ a qualidade do currículo pode ser considerada muito ruim ou razoável. Dado que este segundo grupo revela padrão majoritário de opiniões, havendo uma necessidade premente de se realizar estudo qualitativo, com maior nível de profundidade, de modo a se identificar os cursos nos quais há maior concentração de alunos com esta visão, bem como os fatores apontados por estes para que tal situação se dê.

Por fim, quanto à relevância do estágio curricular obrigatório, a expressiva maioria $(70,1 \%$ ou $\mathrm{n}=411)$ referiu que este aspecto pode ser considerado excelente, muito bom ou bom, embora para uma parcela minoritária de egressos $(23,6 \%$ ou $n=138)$ a relevância do estágio curricular obrigatório podia ser considerada muito ruim ou razoável. O resultado oriundo das opiniões do segundo grupo demanda realizar estudo qualitativo, com maior nível de profundidade, de modo a se identificar os cursos nos quais há maior concentração de alunos com este tipo de visão, bem como os fatores apontados por estes para que esta situação exista. 
Opinião dos egressos sobre as condições de funcionamento do curso de graduação

No que diz respeito à qualidade das salas de aula, a expressiva maioria dos egressos $(74,1 \%$ ou $n=434)$ referiu que este aspecto pode ser considerado excelente, muito bom ou bom. Mas para uma parcela minoritária de egressos $(25,9 \%$ ou $\mathrm{n}=152)$ a qualidade das salas de aula pode ser considerada muito ruim ou razoável. Embora minoritária, esta segunda parcela demanda realizar estudo qualitativo, com maior nível de profundidade, de modo a se identificar os cursos nos quais há maior concentração de alunos com este tipo de visão, bem como os fatores apontados por estes para que esta situação exista.

Com respeito à qualidade dos laboratórios, parcela significativa de egressos $(45 \%$ ou $\mathrm{n}=264)$ referiu que este aspecto pode ser considerado excelente, muito bom ou bom. Não obstante, para a maioria $(51 \%$ ou $\mathrm{n}=299)$ a qualidade dos laboratórios pode ser considerada muito ruim ou razoável. Sendo um padrão majoritário, este segundo grupo demanda realizar estudo qualitativo, com maior nível de profundidade, de modo a se identificar os cursos nos quais há maior concentração de alunos com este tipo de visão, bem como os fatores por esta situação.

No que tange à qualidade do sistema de bibliotecas, parcela significativa de egressos $(44,2 \%$ ou $n=259)$ referiu que este aspecto pode ser considerado excelente, muito bom ou bom. Não obstante, para a maioria $(42,1 \%$ ou $\mathrm{n}=$ 247) a qualidade do sistema de bibliotecas pode ser considerada muito ruim ou razoável. Apesar de minoritário, este segundo grupo demanda realizar estudo qualitativo, com maior nível de profundidade, de modo a se identificar os cursos nos quais há maior concentração de alunos com este tipo de visão, bem como os fatores por esta situação.

Acerca da qualidade dos espaços de convivência, a expressiva maioria de egressos $(54,2 \%$ ou $\mathrm{n}=318)$ referiu que este aspecto pode ser considerado excelente, muito bom ou bom. Contudo, para um grupo significativo $(43,2 \%$ ou $\mathrm{n}=253)$ a qualidade dos espaços de convivência pode ser considerada muito ruim ou razoável. Apesar de minoritário, este segundo grupo demanda realizar estudo qualitativo, com maior nível de profundidade, de modo a se identificar os cursos nos quais há maior concentração de alunos com este tipo de visão, bem como os fatores apontados por estes para que esta situação ainda exista no âmbito institucional.

Finalmente, no que se refere à qualidade da acessibilidade oferecida para o deslocamento de portadores de necessidades físicas, parcela significativa de egressos $(42,1 \%$ ou $n=247)$ referiu que este aspecto pode ser considerado excelente, muito bom ou bom. Não obstante, para um grupo majoritário $(54,8 \%$ 
ou $\mathrm{n}=321)$ a qualidade da acessibilidade oferecida aos portadores de necessidades físicas pode ser considerada muito ruim ou razoável.

\section{Considerações finais}

Devemos recordar que vivemos num contexto de rápida evolução tecnológica, de elevada integração entre corporações, bem como do acirramento da concorrência pelos mercados, aspectos que têm contribuído para dificultar a inserção dos egressos universitários no mundo do trabalho, conforme destacou Sampedro (2002). Recorda Neves (2006) que, atualmente, um computador ligado à internet vale por uma agência bancária. Este exemplo, apesar de caricatural, aplica-se a muitas outras atividades produtivas porque a humanidade convive com os impactos oriundos do uso cada vez mais exacerbado da tecnologia da informação. Tudo leva a crer que vivemos uma era na qual é possível que a economia cresça sem que o nível de emprego acompanhe o mesmo ritmo, graças à capacidade de transferir certas tarefas para as máquinas.

Portanto, há que se romper a cultura do emprego estável, criada ao longo do século XX, e se encarar o desafio de transformar o modelo educacional para criar uma nova perspectiva para os indivíduos, baseada na ideia de educação continuada, pautada na qualificação e requalificação sistemática e ininterrupta, conforme opina Mehedff (1999).

Nesta direção, o documento resultante da Conferência Mundial sobre a Educação Superior para o Século XXI assevera que já não é possível pedir aos sistemas educativos que formem mão de obra para empregos estáveis. A Declaração Mundial sobre a Educação Superior para o Século XXI, no artigo $1^{\circ}$, ressalta como função dos Sistemas de Educação Superior ${ }^{4}$ :

a) formar diplomados altamente cualificados y ciudadanos responsables, capaces de atender a las necesidades de todos los aspectos de la actividad humana, ofreciéndoles cualificaciones que estén a la altura de los tiempos modernos, comprendida la capacitación profesional, en las que se combinen los conocimientos teóricos y prácticos de alto nivel mediante cursos y programas que estén constantemente adaptados a las necesidades presentes y futuras de la sociedad.

4 Disponível em: <http://www.unesco.org/education/educprog/wche/declaration_spa. htm\#declaracion>. Acesso em: 08/04/2004. 
Este novo cenário social justifica e acentua a relevância de estudos sistemáticos dos egressos dos cursos de graduação das IES, posto que o mercado demanda profissionais com perfis adequados a uma nova sistemática produtiva. Por outro lado, a sociedade civil necessita de cidadãos conhecedores dos deveres e bons usuários dos direitos democráticos (ANDRIOLA, 1998).

Desse modo, a formação profissional e cidadã dos recém-graduados deve ser atividade periodicamente e rigidamente avaliada pelos gestores educacionais para que, assim, se possa refletir acerca da adequação da mesma às necessidades do mercado e da sociedade (HARNIK, 2005). Com tais informações poder-se-á planejar e operacionalizar medidas (administrativas e pedagógicas) visando aprimorar a formação dos universitários dos cursos de graduação (ANDRIOLA, 1999). Os resultados obtidos com a pesquisa ora relatada propiciam informações relevantes para os gestores acadêmicos dos cursos de graduação, de modo que estes possam planejar ações de aprimoramento dos processos envolvidos na formação dos universitários deste nível de ensino (ANDRIOLA, 2000, 2001). Para ilustrar a relevância dos resultados, realcemos aspectos que denotam a elevada qualidade da formação dos egressos: a) aumento da proporção de egressos inseridos no mercado de trabalho (passou de $67 \%$ durante a formação para $86 \%$ após a diplomação); b) aumento da proporção de egressos atuando na área de formação do curso de graduação (passou de $75 \%$ durante a formação para $81 \%$ após a diplomação); c) aumento da renda individual, que passou da média de $\mathrm{R} \$ 1.250,00$ (mil duzentos e cinquenta reais) para $\mathrm{R} \$ 2.425,00$ (dois mil, quatrocentos e vinte e cinco reais) após a conclusão da graduação.

Por fim, cabe salientar a relevância dos resultados para o planejamento acadêmico a partir do reconhecimento majoritário dos egressos quanto à qualidade: (i) da formação recebida; (ii) da gestão acadêmica do curso de graduação; (iii) do currículo para o adequado exercício profissional; (iv) do estágio curricular obrigatório; (v) das salas de aula e dos espaços de convivência. No entanto, houve reconhecimento da inadequação de alguns aspectos intrinsecamente vinculados a uma boa formação acadêmica, dentre os quais foram destacados: (i) bibliotecas setoriais; (ii) laboratórios e (iii) acessibilidade dos alunos com necessidades especiais.

Nesse contexto em que se fez menção ao estudo de egressos como importante estratégia para o autoconhecimento e o planejamento institucionais, nos ocorre fazer menção a uma frase atribuída a Lao-Tsé, considerado um dos maiores pensadores e filósofos, que viveu na China por volta do século VI a.C: "quem conhece os outros é sábio; quem conhece a si mesmo é iluminado". 


\section{REFERÊNCIAS}

AMARAL, Nelson Cardoso. A universidade pública no Brasil: identidade e projeto institucional em questão. In: TRINDADE, H. (Org.). Universidade em ruínas na república dos professores. Petrópolis: Vozes, 1999.

ANDRIOLA, Wagner Bandeira. Apresentação de um Modelo Teórico destinado à avaliação dos Programas Estaduais de Qualificação Profissional (PEQs). Ensaio. Avaliação e Políticas Públicas em Educação, Rio de Janeiro, v. 19, n. 6, p. 259-266, 1998.

ANDRIOLA, Wagner Bandeira. Evaluación: La vía para la calidad educativa. Ensaio. Avaliação e Políticas Públicas em Educação, Rio de Janeiro, v. 7, n. 25, p. 355-368, 1999.

ANDRIOLA, Wagner Bandeira. Calidad educativa y efectividad escolar: conceptos y características. Educação em Debate, Fortaleza, v. 39, n. 1, p. 7-14, 2000.

ANDRIOLA, Wagner Bandeira. Factores caracterizadores de centros educativos eficaces. Bordón: Revista de Pedagogía, Madrid, v. 53, n. 2, p. 175-183, 2001.

ANDRIOLA, Wagner Bandeira. Evasão discente no âmbito da Universidade Federal do Ceará (UFC): proposta para identificar suas causas e implantar um serviço de Orientação e Informação (SOI) para os egressos do ensino médio. In: ENCONTRO DE PESQUISA EDUCACIONAL DO NORTE E NORDESTE, 16. Anais... São Cristóvão: Universidade Federal de Sergipe, 2003a.

ANDRIOLA, Wagner Bandeira. Evasão discente na Universidade Federal do Ceará (UFC): proposta para identificar suas causas e implantar um serviço de Orientação e Informação (SOI). Ensaio. Avaliação de Políticas Públicas em Educação, Rio de Janeiro, v. 11, n. 40 , p. $332-347,2003$ b.

ANDRIOLA, Wagner Bandeira. Avaliação diagnóstica dos egressos de 2003 e 2004 dos cursos de graduação da Universidade Federal do Ceará (UFC). Avaliação. Revista da Rede de Avaliação Institucional da Educação Superior, Sorocaba, v. 11, n. 4, p. 129-152, 2006.

ANDRIOLA, Wagner Bandeira; McDONALD, Brendan Coleman. Avaliação: Fiat Lux em Educação. Fortaleza: Editora da Universidade Federal do Ceará, 2003.

BARDAGI, Marucia Patta; BIZARRO, Liziane; ANDRADE, Ana Maria Jung; AUDIBERT, Alyane; LASSANCE, Maria Célia Pacheco. Avaliação da formação e trajetória profissional na perspectiva de egressos de um curso de Psicologia. Psicologia: Ciência e Profissão, Brasília, v. 28, n. 2, p. 304-315, 2008.

BELLONI, Isaura. Avaliação institucional: um instrumento de democratização da educação. Linhas Críticas, Brasília, v. 5, n. 9, p. 7-30, 1999.

BRASIL. Sistema Nacional de Avaliação da Educação Superior. Diretrizes para a Avaliação das Instituições de Educação Superior. Brasília: INEP, 2004.

CARRIJO, Clarissa Irineu de Sousa; BEZERRA, Ana Lúcia Queiroz; MUNARI, Denize 
Bouttelet; MEDEIROS, Marcelo. A empregabilidade de egressos de um curso em enfermagem. Revista de Enfermagem da UERJ, Rio de Janeiro, v. 15, n. 3, p. 356-363, 2007.

CAVALIERI, Adriane; MACEDO-SOARES, Diana; THIOLLENT, Michel. Avaliando o desempenho da Universidade. São Paulo: Loyola, 2004.

COLENCI, Raquel; BERTI, Heloísa Wey. Formação profissional e inserção no mercado de trabalho: percepções de egressos de graduação em enfermagem. Revista da Escola de Enfermagem da USP, São Paulo, v. 46, n. 1, p. 158-166, 2012.

CORDIOLI, Otavio Genta; BATISTA, Nildo Alves. A graduação em Odontologia na visão de egressos: propostas de mudanças. Revista da ABENO, São Paulo, v. 7, n. 1, p. 88-95, 2007.

CUNHA, Aparecida Miranda; TUNES, Elizabeth; SILVA, Roberto Ribeiro. Evasão do curso de Química da Universidade de Brasília: a interpretação do aluno evadido. Química Nova, Brasília, v. 24, n. 1, p. 262-280, 2001.

D’AMBROSIO, Ubiratan. Os problemas da Matemática que não são numéricos. Jornal da UNESP, São Paulo, Ano XII, n. 114, 1997.

DIAS SOBRINHO, José; RISTOFF, Dilvo Ivo (Org.). Avaliação e compromisso público: A Educação Superior em debate. Florianópolis: Insular, 2003.

GAMBARDELLA, Ana Maria; FERREIRA, Cláudia Franchi; FRUTUOSO, Maria Fernanda. Situação profissional de egressos de um curso de nutrição. Revista de Nutrição, Campinas, v. 13, n. 1, p. 37-40, 2000.

GELL-MANN, Murray. El quark y el jaguar. Barcelona: Tusquets, 2003.

HARNIK, Simone. Má escolha é a maior causa de evasão. 18 out. 2005. Disponível em: <http://www1.folha.uol.com.br/folha/educacao/ult305u17930.shtml >. Acesso em: 08/08/2006.

LOTUFO, Ana Diva; SOUSA JR, José Carlos; COVACIC, Márcio; BRITO, Jorge. A evasão e repetência escolar relacionadas com a metodologia de ensino. Anais do XXV Congresso Brasileiro de Ensino de Engenharia (COBENGE), p. 2148-2160, Salvador, 1997.

LOTUFO, Ana Diva; SOUSA JR, José Carlos; COVACIC, Márcio; BRITO, Jorge. Evasão e repetência na FEIS/UNESP: análise e resultado. Anais do XXVI Congresso Brasileiro de Ensino de Engenharia (COBENGE), p. 185-203, São Paulo, 1998.

MEHEDFF, Nassim Gabriel. A avaliação da educação e a inserção dos egressos do ensino médio no mercado de trabalho. Brasília: Instituto Nacional de Estudos e Pesquisas Educacionais (INEP), 1999.

MEIRA; Maria Dirce; KURCGANT, Paulina. O ensino de administração na graduação: percepção de enfermeiros egressos. Texto \& Contexto Enfermagem, Florianópolis, v. 18, n. 4, p. 670-679, 2009. 
NEVES, Ricardo. O emprego já era! Revista Época, Seção Sua Bússola, p. 54, abr. 2006. PAREDES, Alberto Sànches. A evasão do terceiro grau em Curitiba. Documento de Trabalho NUPES, 6/94. São Paulo: Núcleo de Pesquisa sobre Ensino Superior da Universidade de São Paulo, 1994.

POPPER, Karl. A lógica da pesquisa científica. São Paulo: Cultrix, 1972.

PUENTE VIEDMA, Carlos. SPSS/PC+. Una guía para la investigación. Madrid: Editorial Complutense, 1993.

QUEM é o profissional que sai da UnB? Jornal da Ciência, Sociedade Brasileira para o progresso da Ciência-SBPC, 2005.

RAMOS, Mozart Neves. Vestibular e evasão. Artigo publicado no Jornal do Commércio de Recife, 29 de setembro de 1998. Disponível em: <http://www2.uol.com.br/ JC/_1998/2909/art2909.htm>. Acesso em: 24/05/2014.

RISTOFF, Dilvo Ivo. Avaliação institucional. Pensando princípios. In: BALZÁN, Newton César; DIAS SOBRINHO, José (Org.). Avaliação institucional. Teoria e experiências. São Paulo: Cortez, 2000. p. 37-51.

ROCHA, Belchior de Oliveira; FILGUEIRA, João Maria; DA COSTA, Liznando Fernandes; GALVÃO, Leísia; VIANA, Rafael. Egressos do CEFET/RN: avaliação da formação, inserção no mundo do trabalho e perspectiva de requalificação. Holos, Rio Grande do Norte, Ano 21, p. 47-56, 2005.

SAMPEDRO, José Luís. El mercado y la globalización. Madrid: Ediciones Destino, 2002.

SANTOS, Carlos Eduardo; SANNA, Maria Cristina. Inserção dos egressos do curso de graduação em enfermagem de uma universidade particular do grande ABC no mercado de trabalho. Revista Brasileira de Enfermagem, Brasília, v. 56, n. 6, p. 630-633, 2003.

SCHIBIK, Sílvia. O desafio de se manter na universidade. Disponível em: < http://www. andifes.org.br/news.php?offset $=0 \&$ where $=>$. Acesso em: 08/04/2008.

SERRES, Michel. Historia de las ciencias. Madrid: Editora Cátedra, 1998.

WILSON, Edward Osborne. Consilience: the unity of knowledge. New York: Vintage Books, 1999.

Texto recebido em 03 de junho de 2014. Texto aprovado em 26 de setembro de 2014. 
